\title{
The Improvements of the Backhoe-Loader Arms
}

\author{
Ahmet Erklig*, Eyüp Yeter \\ Department of Mechanical Engineering, Faculty of Engineering, University of Gaziantep, Gaziantep, Turkey \\ Email: "erklig@gantep.edu.tr, eyeter@gantep.edu.tr
}

Received December 10, 2012; revised January 10, 2013; accepted January 18, 2013

Copyright (C) 2013 Ahmet Erklig, Eyüp Yeter. This is an open access article distributed under the Creative Commons Attribution License, which permits unrestricted use, distribution, and reproduction in any medium, provided the original work is properly cited.

\begin{abstract}
In this study, static structural analysis of backhoe-loader arms has been performed with the finite element method (FEM). The aim of this study is to simulate and strengthen the back and front arms of the backhoe-loader concerning with stress under maximum loading condition and different boundary conditions. According to analysis result, back and front arms of the backhoe-loader are strengthened with the use of reinforcements. As a result of the study, strength of the arms has been increased by nearly $20 \%$.
\end{abstract}

Keywords: Backhoe-Loader; Finite Element Simulation; ANSYS

\section{Introduction}

Backhoe-loader is a mobile machine which digs, elevates, loads and swings materials by the action of its mechanism consisting of backhoe and loader parts as shown in Figure 1.

Backhoe-loader parts such as boom, arm, and loader arm limit the life expectancy of the backhoe loader. Therefore, backhoe loader parts must be strong enough to cope with caustic working conditions. It can be concluded that, strength analysis is an important step in the design of backhoe loader parts.

Finite element analysis (FEA) is the most powerful technique in the strength calculations of the structures working under known loads and boundary conditions. These analyses show the critical points of the design early and so one can improve the design before producing prototypes.

In literature, there are many studies on FEA of moving machines (backhoe-loader, excavator, bucket wheel excavator act.). Yeter [1] studied the analysis of backhoeloader using ANSYS Workbench finite element program. Özer [2] studied strength analysis of boom-stick groups (Backhoe-loader back arms) having different digging reach by using FEA method. Çetin [3] designed and analyzed a demolition boom for hydraulic excavator with operation weight of 30 tons. Firstly, the mechanism design was performed to determine the basic link dimensions. In the second step, the structural shape of the boom was estimated to perform static stress analysis.

${ }^{*}$ Corresponding author.
Smolnicki et al. [4] applied the FEA for the rotation joint of the single-bucket excavator. Stress distribution for the extreme load conditions was determined by using the FEA for the jib boom. Bosnjak et al. [5] analyzed bucket wheel excavator portal tie-rod support. Rusinski et al. [6] performed the finite element analysis of a mine's loader boom. Karlinski et al. [7] used the FEM to analyze protective structures for construction and mining machine operators. The principles of constructing calculation models for numerical simulations in virtual space by the finite element method were given. A detailed example of FEM tests on a protective structure was provided. Miralbes and Castejon [8] presented a new methodology of calculation by means of the FEA applied to crane jibs. This analysis has been carried out in terms of strength and stiffness, and for any type of crane jib: telescopic crane, lattice crane, closed beam crane, etc. Different

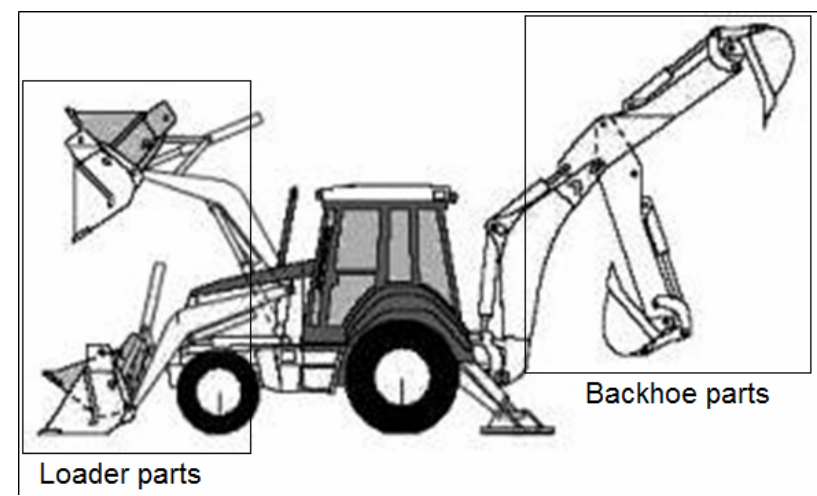

Figure 1. Backhoe-loader machine. 
load cases and boundary conditions that the structure should bear were simulated. Derlukiewicz and Przybylekv [9] studied strength analysis of telescopic jib mounted on mobile platform. FEA is performed to see maximum stress points and to make construction design optimization. Croccolo et al. [10] performed finite element analysis of static structural of an articulated urban bus chassis. Solid (3D) and shell (2D) elements were used in the analysis with the use of ANSYS.

In literature, finite element analyses are used in design improvement and optimization purposes for many machine parts. This study aims to improve backhoe-loaders' back and front arms. To achieve this, backhoe-loader's back arm and front arm have been analyzed under maximum loads and different boundary conditions. The front arm has been analyzed with four different conditions, symmetrical and unsymmetrical loading while loader cylinder is active and symmetrical and unsymmetrical loading while bucket cylinder is active. The back arm has been analyzed with two different conditions, loading while arm cylinder is active and loading while bucket cylinder is active. The analysis has been carried out using ANSYS Workbench finite element packet program. Maximum stress locations and reinforcement were both determined and applied. Strength of the arms has been increased after improvements.

\section{Analysis of Front and Back Arm}

Front and back arm which are the most critical parts of backhoe loader were analyzed. Solid geometries of front and back arm are given in Figures 2(a) and (b) respectively.

Assumptions used in the analysis are:

- Material behavior is linear elastic and strains are small. Therefore, linear elastic analysis will be carried out.

- Pins and links are assumed as rigid.

- The loads are applied statically. (For loader arm unsymmetrical loading also examined)

- Material properties of structures after heat treatment (welding operation) are not changing.

\subsection{Maximum Breakout Force of Arms}

\subsubsection{Maximum Breakout Force of the Front Arm}

Loader and bucket hydraulic cylinders are control the front arm. According to loader and bucket cylinder maximum pressure, breakout forces $\left(\mathrm{W}_{\mathrm{bf}}\right)$ were calculated using free body diagrams of the arm (Figures 3(a) and (b)). Maximum breakout force was obtained while bucket cylinder active as $78.88 \mathrm{kN}$ and it was used in the analysis of the front arm with two different boundary conditions.

\subsubsection{Maximum Breakout Force of Back Arm}

Two hydraulic pistons are used to control back arm. With

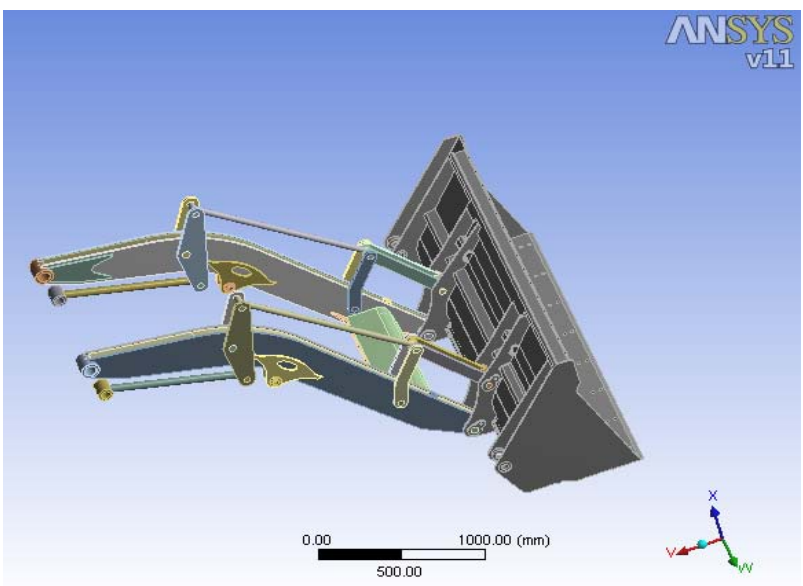

(a)

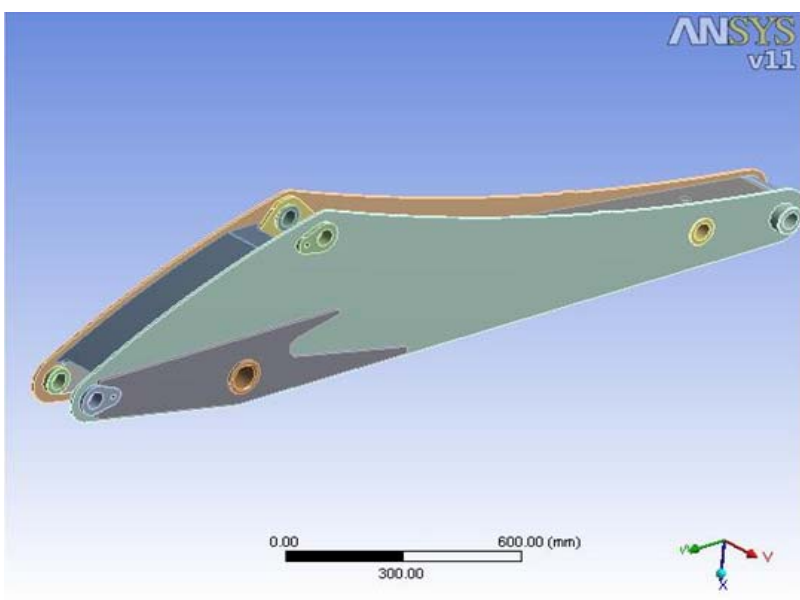

(b)

Figure 2. Backhoe-loader arms solid models. (a) Front arm; (b) Back arm.

the use of maximum hydraulic pressure, maximum breakout force was calculated as $50.68 \mathrm{kN}$ of bucket piston. Joint forces (F4, F5, F6, F7, and F8) were calculated as $149.02 \mathrm{kN}, 139.42 \mathrm{kN}, 11.59 \mathrm{kN}, 33.39 \mathrm{kN}$, and 33.16 $\mathrm{kN}$ respectively as given in Figure 4.

\subsection{Finite Element Analysis}

Main parts of the front arm are St52-3 and bushes and pins are SAE 1040 steel. Material properties are given in Table 1. Finite element model of the front arm (Figure 5(a)) has 223,697 nodes and 73,716 3D solid elements. Finite element model of the back arm (Figure 5(b)) has 264,048 nodes and 65,708 solid elements. Solid 186 and Solid 187 element types are used. Solid 186 is a higher order 3D 20 noded and Solid 187 is a higher order 3D 10 noded solid element [11].

\subsection{Boundary Conditions for Arms}

In order to determine maximum stress points, two bound- 


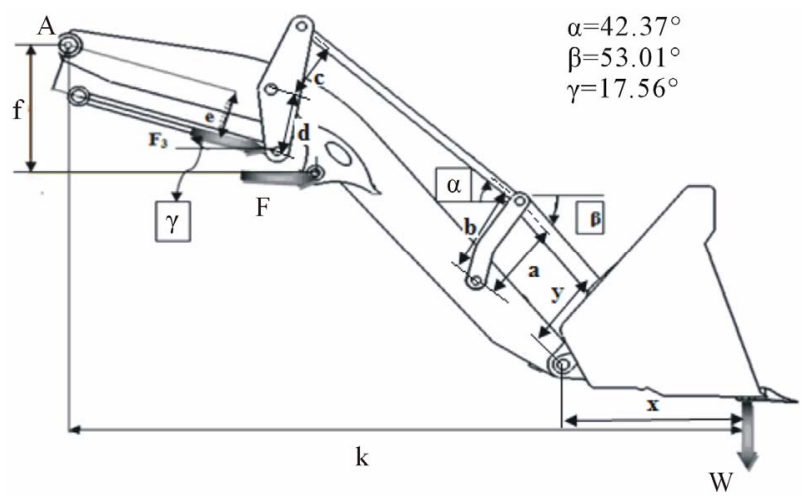

(a)

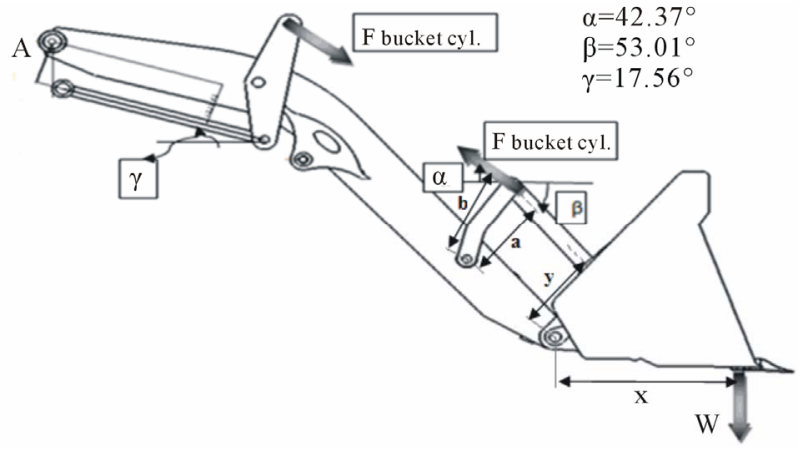

(b)

Figure 3. Free body diagram of loader arm. (a) While loader cylinder is active; (b) While bucket cylinder is active.

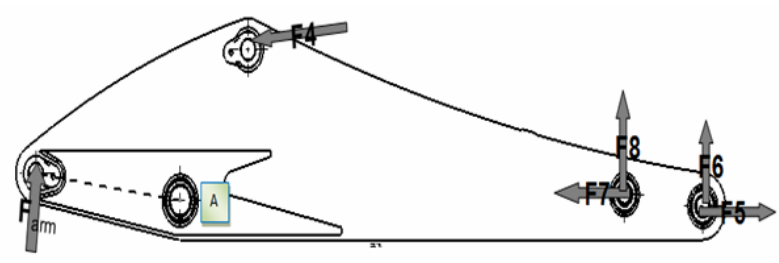

Figure 4. Joint forces while bucket cylinder active.

Table 1. Material properties of St52-3 and SAE 1040.

\begin{tabular}{ccc}
\hline & St52-3 & SAE 1040 \\
\hline Young's Modulus (GPa) & 210 & 200 \\
Poisson's Ratio & 0.3 & 0.29 \\
Tensile Yield Strength (MPa) & 355 & 415 \\
Tensile Ultimate Strength (MPa) & 520 & 600 \\
\hline
\end{tabular}

ary conditions of the front arm conditions of the system were examined;

- While loader cylinder is active,

- Symmetric loading

- Unsymmetrical loading

- While bucket cylinder is active,

- Symmetric loading

- Unsymmetrical loading

In order to determine maximum stress points, two boundary conditions of the back arm of the system were examined;

- While arm cylinder is active;

- While bucket cylinder is active.

Maximum breakout force was calculated from the bucket cylinder pressure.

\section{Finite Element Analysis of Arms}

\subsection{FEA Results of the Front Arm}

FEM analyses have been carried out for different loading conditions. Unsymmetrical loading while bucket cylinder is active is the most critical loading conditions so only results of these loading conditions was given with details.

Equivalent stress distribution of loader while bucket cylinder is active and unsymmetrical loading is shown in the Figure 6. The maximum equivalent stress value was calculated as $322.39 \mathrm{MPa}$.

To reduce the stress values of the arm two improvements have been done as:

First improvement was carried out by increasing thickness of the left and right side outer side parts of the arm from 8 to $10 \mathrm{~mm}$.

- Second improvement was carried out by changing shape of the support as given Figure 7. Finite element analyses were carried out using improved geometry for symmetric and unsymmetrical loading while loading cylinder is active.

Finite element analyses have been performed for the improved arm. Different boundary conditions results were given in the Table 2.

The analysis has been carried out considering unsymmetrical loading while bucket cylinder is active and the equivalent stress distribution of loader is shown in Figures 8 and 9. Maximum equivalent stress was reduced to $268 \mathrm{MPa}$ from $322 \mathrm{MPa}$ with improvements.

As seen from the Table 2, while loader cylinder is active and after improvements the maximum stress was reduced to $162.34 \mathrm{MPa}$ from $182.62 \mathrm{MPa}$ for symmetrical loading. While bucket cylinder is active the maximum stress was reduced to $268.98 \mathrm{MPa}$ from $322.39 \mathrm{MPa}$ for unsymmetrical loading.

\subsection{FEA Results of the Back Arm}

Equivalent stress distribution of the back arm is shown in the Figures 10-12. Maximum equivalent stress in the arm was calculated as $222.83 \mathrm{MPa}$.

To reduce the maximum stress two improvements have been performed to the maximum stressed points. First reinforcement was carried out by putting circular plate back of outer plates (Figure 13). Second improvement was carried out by changing original reinforced plate that putted on face of outer plates (Figure 14).

After both improvements, equivalent stress result is 


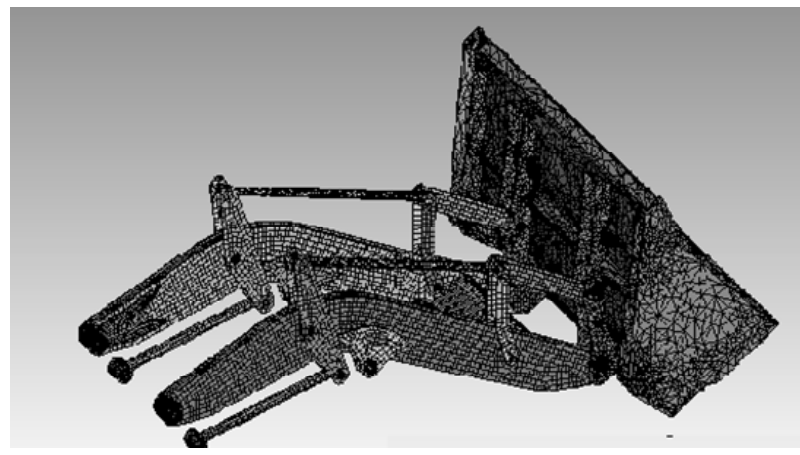

(a)

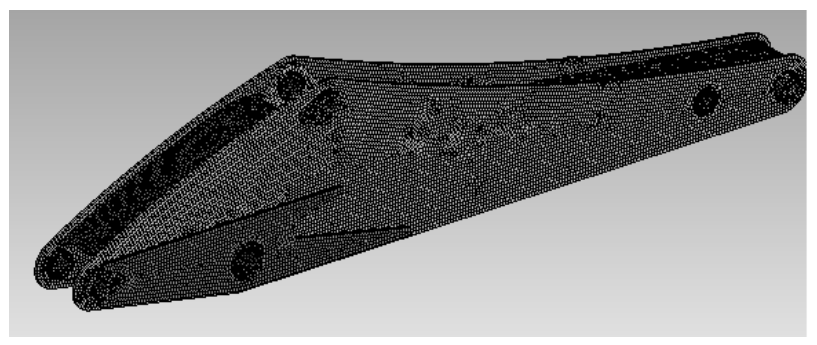

(b)

Figure 5. Finite element model of the arm. (a) Loader arm; (b) Back arm.

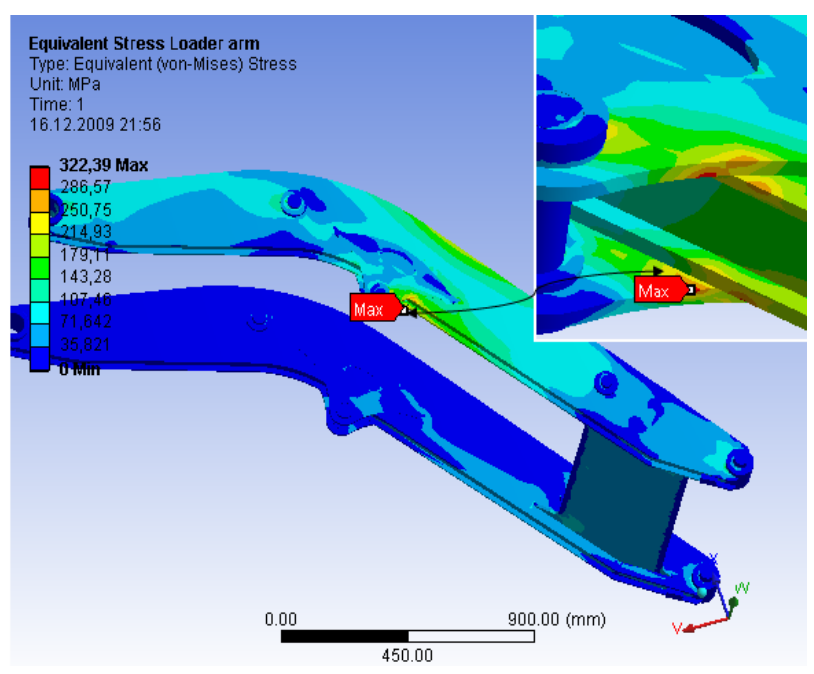

Figure 6. Equivalent stress distribution of loader arm while bucket cylinder is active. (a)

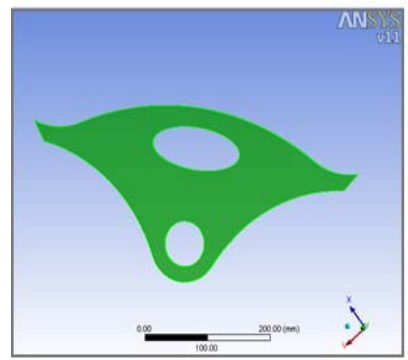

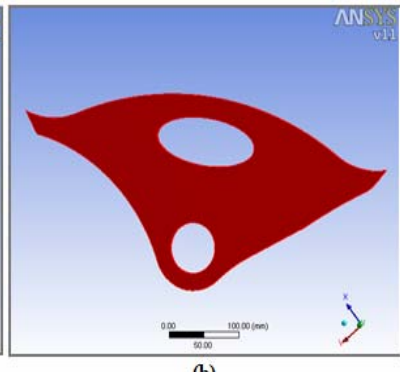

(b)
Figure 7. Original (a) and modified arm (b) support part.
Table 2. Comparisons of maximum stress points of original front arm and improved arm for each loading types while bucket cylinder is active.

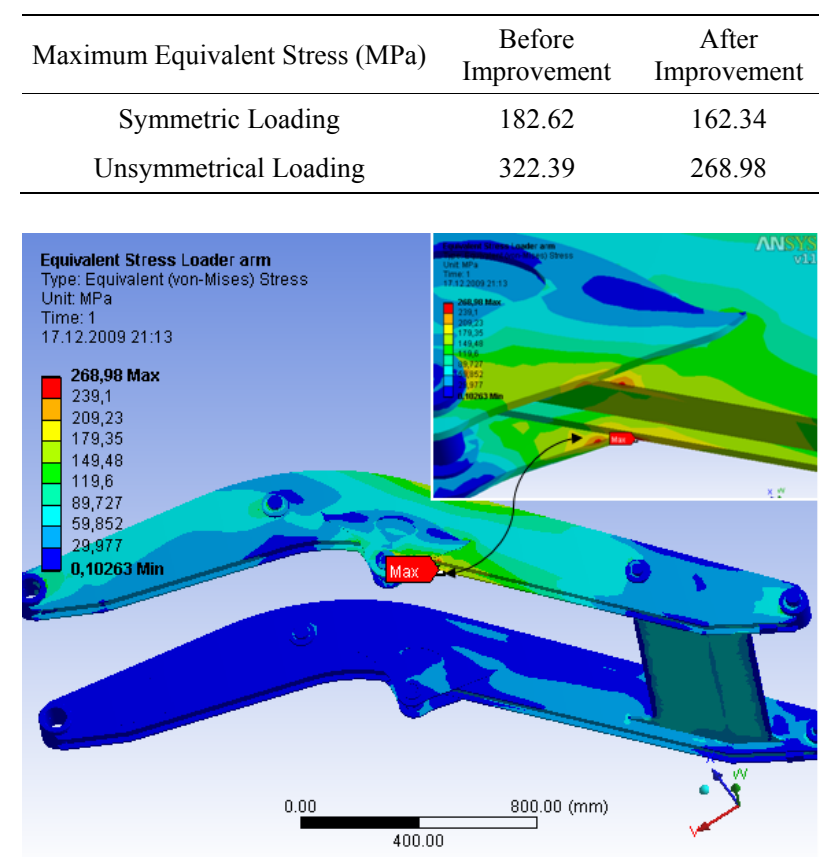

Figure 8. Equivalent stress distribution of loader arm.

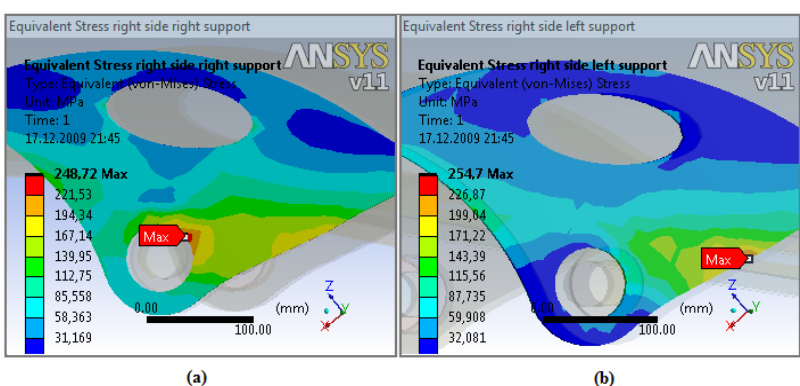

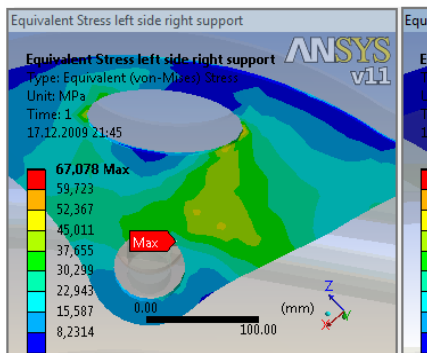

(c)

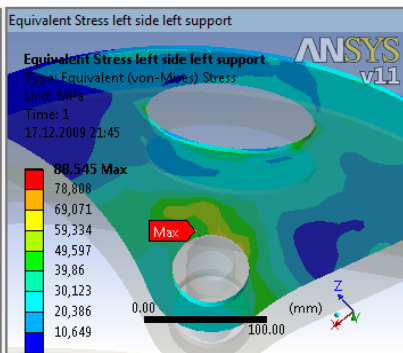

(d)
Figure 9. Equivalent stress distribution of unsymmetrical loading while bucket cylinder is active with new improvement. (a) Loader arm right side right support; (b) Loader arm right side left support; (c) Loader arm left side right support; (d) Loader arm left side left support.

shown in the Figure 15. According to results maximum equivalent stress of whole structure was reduced to 179 $\mathrm{MPa}$. Maximum equivalent stress of right and left outer plates was reduced to $140 \mathrm{MPa}$. 


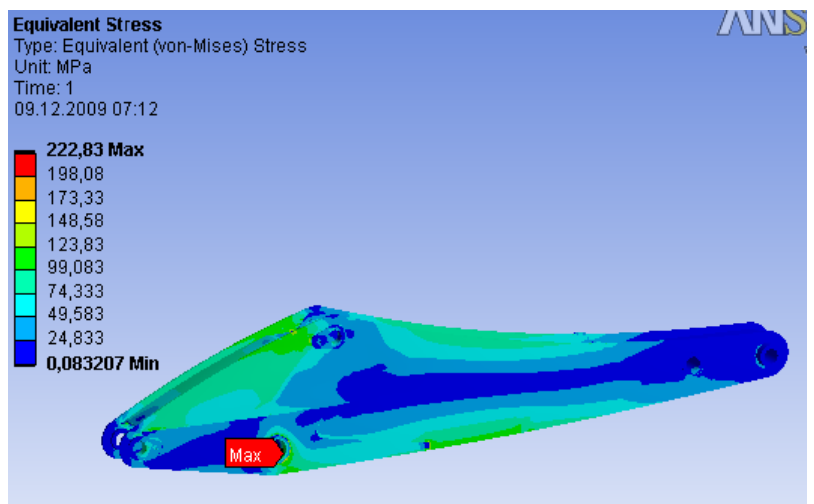

Figure 10. Equivalent stress distribution of back arm.

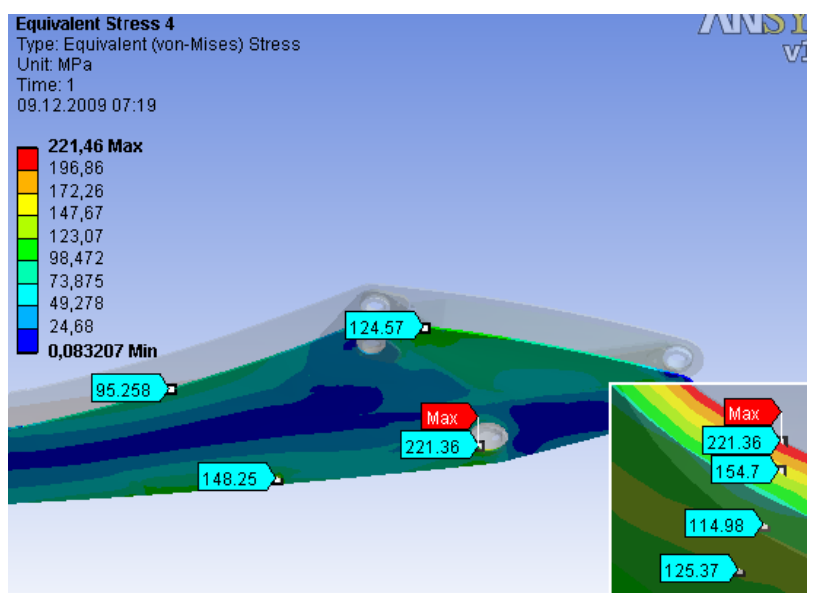

Figure 11. Equivalent stress distribution of original back arm left part.

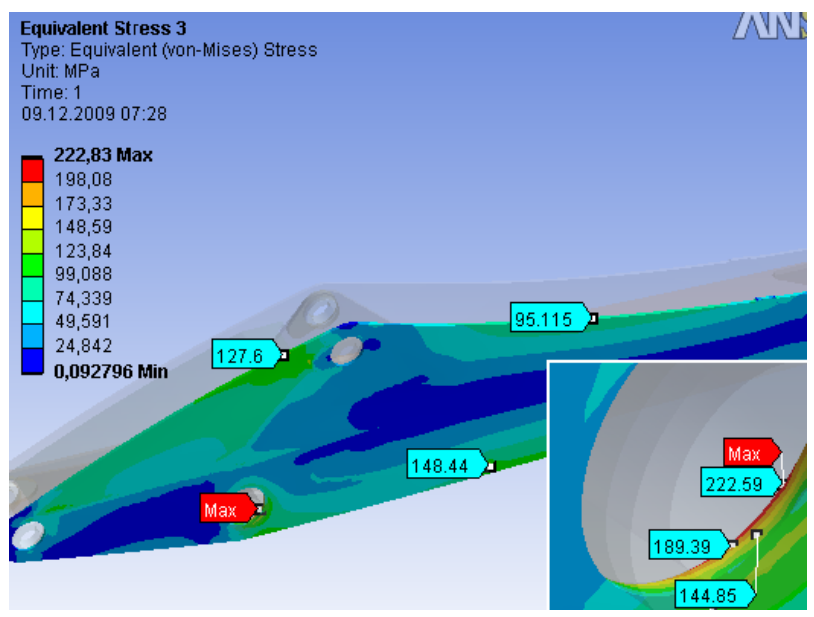

Figure 12. Equivalent stress distribution of original back arm right part.

\section{Safety Factor}

Generally safety factor can be defined as the ratio of the ultimate strength of material to allowable stress. Figure 16 shows safety factor of the front arm before improvement and after improvement at the symmetrical loading

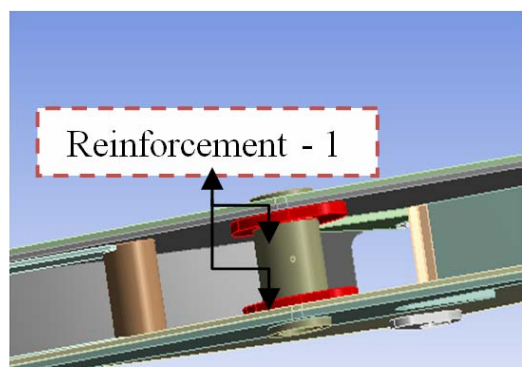

Figure 13. Back arm with reinforcement.

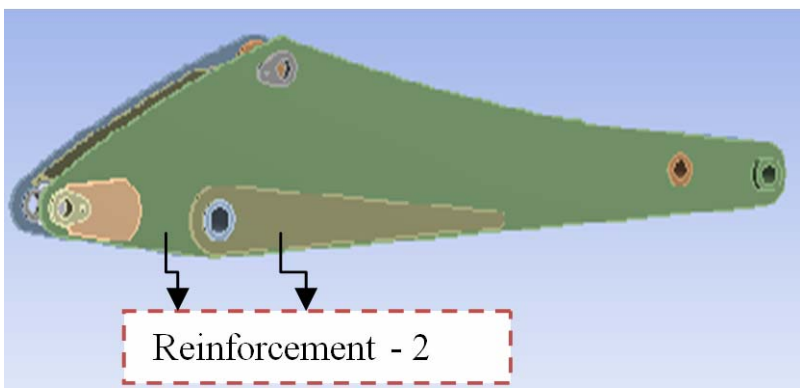

Figure 14. Original back arm with new reinforcement-2.

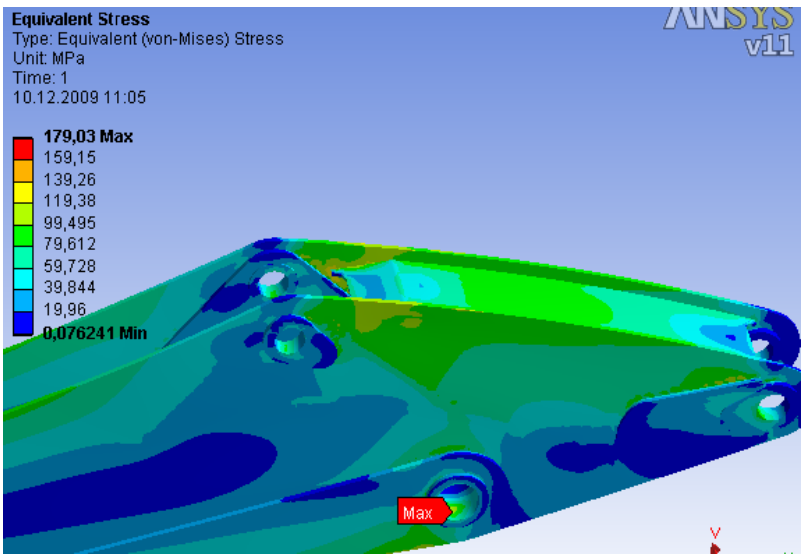

Figure 15. Equivalent stress distribution of back arm with both improvements.

while loader cylinder is active. As seen from the Figure safety factor has increased to 2.18 from 1.94. As seen from the Figure safety factor has increased to 1.32 from 1.10 .

Figure 17 shows safety factors of back arm before and after improvements. As seen from the Figure minimum safety factor has increased to 1.98 from 1.59.

\section{Conclusions}

The backhoe-loader back and front arm have been analyzed with the maximum loads and boundary conditions using FEM. ANSYS workbench FEA program has been used in the analysis. Analyses have been carried out for the maximum hydraulic cylinder forces. Symmetrical and unsymmetrical boundary conditions have been examined. 


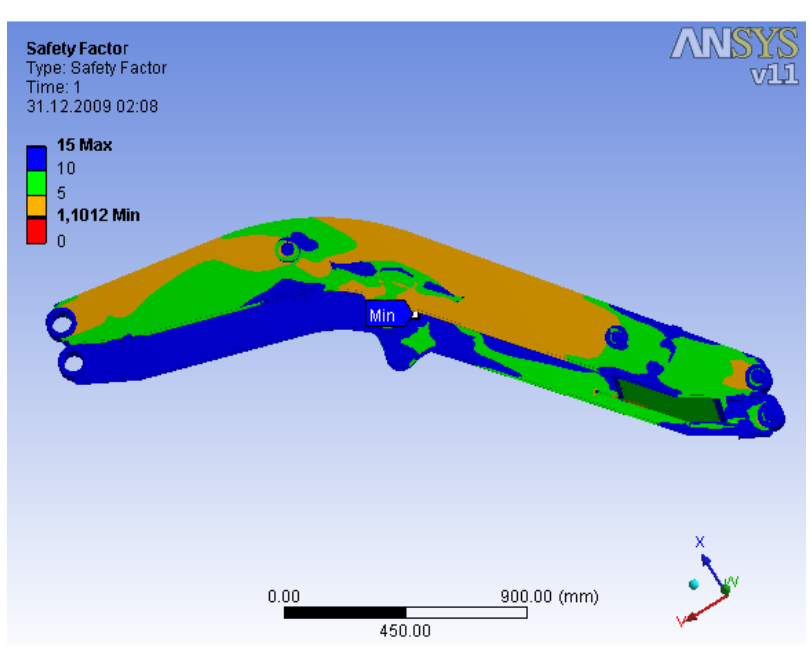

(a)

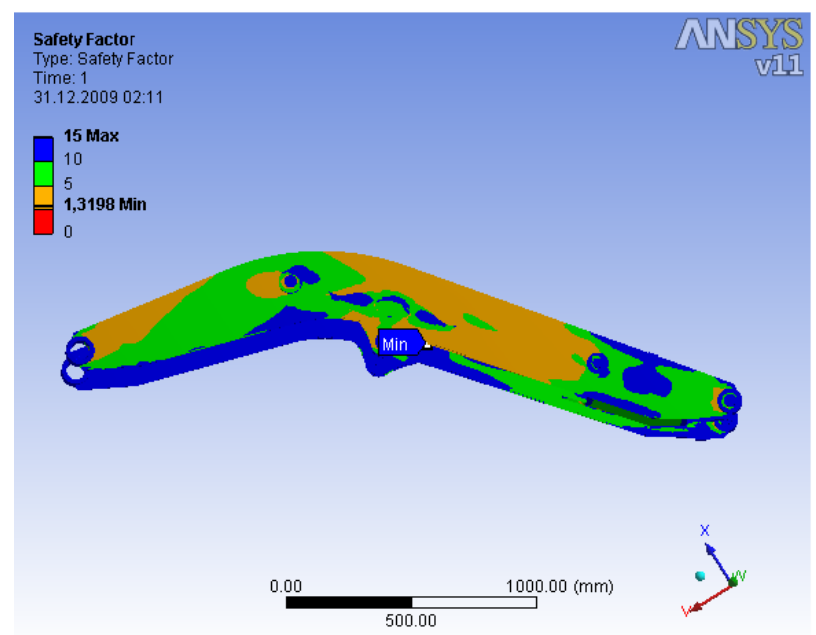

(b)

Figure 16. Safety factors of symmetrical loading while loader cylinder is active with new improvement. (a) Before improvements; (b) After improvements.

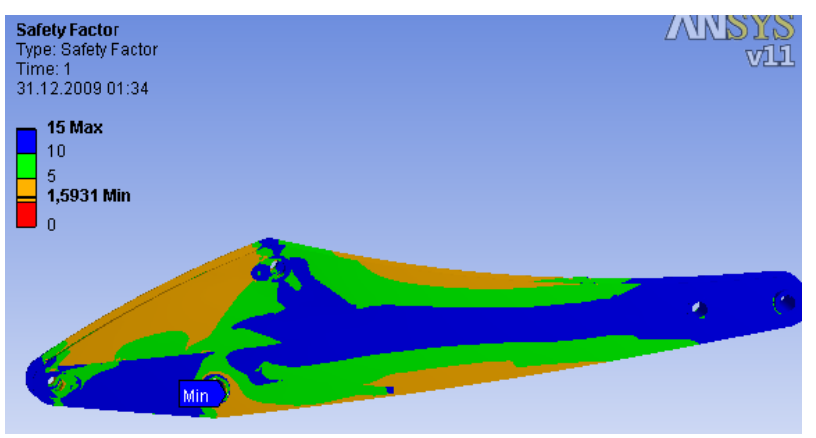

(a)

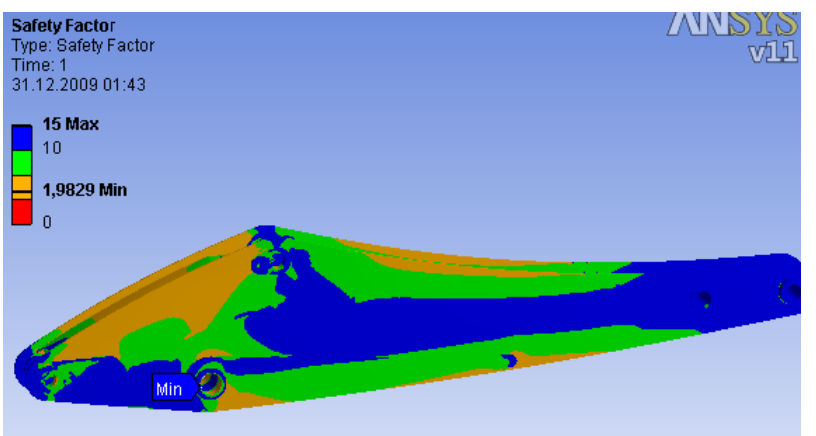

(b)

Figure 17. Safety factor of back arm. (a) Before improvements; (b) After improvements.

With respect to analyses results, the backhoe-loader arms need an improvement to increase its strength. Two different improvements have been performed for arms. After improvements, safety factor is increased to 1.98 from 1.59 for back arm. Strength of the back arm has been increased by $24.5 \%$. For front arm, safety factor has been increased to 2.18 from 1.94 at the symmetrical loading while loader cylinder is active. Strength has been increased by $12.37 \%$. Safety factors have been increased to 1.32 from 1.10 at the unsymmetrical loading while bucket cylinder is active. Strength of the front arm has been increased by $20 \%$.

\section{REFERENCES}

[1] E. Yeter, "Improvement of Backhoe-Loader Back and Front Arms," Ms.c. Thesis, Gaziantep University, Gaziantep, 2009.

[2] S. Özer, "Kazıc1-Yükleyicilerde Kazma Mesafesine Bağlı Olarak Bom-Stik Grubunun Tasarımı," Ms.c. Thesis, Mersin University, Mersin, 2007.

[3] B. Çetin, "Design of a Demolition Boom," Ms.c. Thesis,
Middle East Technical University, Ankara, 2007.

[4] T. Smolnicki, D. Derlukiewicz and M. Stancoe, "Evaluation of Load Distribution in the Superstructure Rotation Joint of Single-Bucket Caterpillar Excavators," Journal of Automation in Construction, Vol. 17, No. 3, 2008, pp. 218223. http://dx.doi.org/10.1016/j.autcon.2007.05.003

[5] S. Bosnjak, Z. Petkovic, N. Zrnic, G. Simic and A. Simonovic, "Cracks, Repair and Reconstruction of Bucket Wheel Slewing Excavator Platform," Engineering Failure Analysis, Vol. 16, No. 5, 2009, pp. 1631-1642. http://dx.doi.org/10.1016/j.engfailanal.2008.11.009

[6] E. Rusinski, J. Czmochowski and P. Moczki, "Numerical and Experimental Analysis of a Mine's Loader Boom Crack," Journal of Achievements of Materials and Manufacturing Engineering, Vol. 17, No. 1-2, 2006, pp. 273276.

[7] J. Karlinski, E. Rusinski and T. Smolnicki, "Protective Structures for Construction and Mining Machine Operators," Journal of Automation in Construction, Vol. 17, No. 3, 2008, pp. 232-244 http://dx.doi.org/10.1016/j.autcon.2007.05.008

[8] R. Miralbes and L. Castejon, "Design and Optimization of Crane Jibs for Forklift Trucks," Proceedings of the 
World Congress Analysis, London, 2009.

[9] D. Derlukiewicz and G. Przybylek, "Chosen Aspects of FEM Strength Analysis of Telescopic Jib Mounted on Mobile Platform," Journal of Automation in Construction, Vol. 17, No. 3, 2008, pp. 278-283. http://dx.doi.org/10.1016/j.autcon.2007.05.009

[10] D. Croccolo, M. De Agostinis and N. Vincenzi, "Struc- tural Analysis of an Articulated Urban Bus Chassis via FEM: A Methodology Applied to a Case Study," Strojniski vestnik-Journal of Mechanical Engineering, vol. 57, No. 11, 2011, pp. 799-809.

[11] ANSYS User's Manual, "Release 11.0 documentation for ANSYS Workbench," 2007. 